\title{
Re: Abdel-Kader MS. Evaluation of the efficacy of sexual intercourse in expulsion of distal ureteric stones. Int Urol Nephrol 2016 [Epub ahead of print]
}

\author{
Yunjin Bai ${ }^{1}$ Ping Han ${ }^{1} \cdot$ Jia Wang ${ }^{1}$
}

Received: 16 November 2016 / Accepted: 18 November 2016 / Published online: 23 November 2016

(C) Springer Science+Business Media Dordrecht 2016

\section{Editor,}

We read this article [1] with great interest and appreciate the work of the authors. The authors recommended that practicing sexual intercourse for 3-4 times/week for married male patients with distal ureteric stone $(5-10 \mathrm{~mm})$ increases the expulsion rate and decreases the frequency of renal colic and the needs for analgesic. These results are consistent with previous study by Doluoglu et al. [2]. Doluoglu et al. assumed sexual intercourse facilitates the ureteric stone expulsion associated with nitric oxide-mediated pathway.

As we know, phosphodiesterase type 5 inhibitors (PDE5Is) act on the nitric oxide-mediated pathway of smooth muscles, resulting in increased levels of cyclic guanosine monophosphate, causing ureteric relaxation. On the basis of theory, many studies have shown that distal ureteral stones can be successfully treated with different PDE5Is. Jayant et al. [3] conducted a randomized controlled trial to compare the efficacy of tamsulosin versus tamsulosin plus tadalafil as medical expulsive therapy for lower ureteric stones $(5-10 \mathrm{~mm})$ and found the addition of tadalafil with tamsulosin able to facilitate the ureteric stone expulsion. Recently, Shokeir et al. [4] found sildenafil citrate enhances spontaneous passage of 5-10 mm distal ureteric stones. Therefore, we have reasons to believe that sexual intercourse facilitates the ureteric stone expulsion associated with nitric oxide-mediated pathway. In addition, this study by Abdel-Kader further consolidated the role for PDE5Is in the medical treatment of distal ureteric stones.

\section{References}

1. Abdel-Kader MS (2016) Evaluation of the efficacy of sexual intercourse in expulsion of distal ureteric stones. Int Urol Nephrol. doi:10.1007/s11255-016-1448-z

2. DA Doluoglu OG, Kilinc MF, Karakan T, Kabar M, Bozkurt S, Resorlu B (2015) Can sexual intercourse be an alternative therapy for distal ureteral stones? A prospective, randomized. Controll Study. Urol 86(1):19-24

3. Jayant KAR, Agrawal S (2014) Tamsulosin versus tamsulosin plus tadalafil as medical expulsive therapy for lower ureteric stones: a randomized controlled trial. Int $\mathrm{J}$ Urol 21(10):1012-1015

4. Shokeir AATM, Abolazm AE, Harraz A (2016) Sildenafil citrate as a medical expulsive therapy for distal ureteric stones: a randomised double-blind placebo-controlled study. Arab J Urol 14(1):1-6
Jia Wang

wangjiawch@163.com

1 Department of Urology, Institute of Urology, West

China Hospital, Sichuan University, Guoxue Xiang\#37,

Chengdu 610041, Sichuan, China 